\title{
Endocannabinoids Link Feeding State and Auditory Perception-Related Gene Expression
}

\author{
Ken Soderstrom, ${ }^{1}$ Qiyu Tian, ${ }^{1}$ Marta Valenti, ${ }^{2}$ and Vincenzo Di Marzo ${ }^{2}$ \\ ${ }^{1}$ Department of Pharmacology and Toxicology, Brody School of Medicine, East Carolina University, Greenville, North Carolina 27834, and \\ 2Endocannabinoid Research Group, Istituto di Chimica Biomolecolare, Consiglio Nazionale delle Ricerche, 80078 Pozzuoli, Naples, Italy
}

\begin{abstract}
Singing by adult male zebra finches is a learned behavior important for courtship, kin recognition, and nest defense (Zann, 1996) and is inhibited by both brief periods of limited food availability and systemic injection of cannabinoids. These similar effects on singing, combined with increasing evidence for endocannabinoid involvement in feeding behavior, led us to evaluate a possible shared mechanism. We found that limited food availability both reduces singing in a cannabinoid antagonist-reversible manner and increases levels of the endocannabinoid 2-arachidonyl glycerol in various brain regions including the caudal telencephalon, an area that contains auditory telencephalon including the L2 subfield of L (L2) and caudal medial nidopallium (NCM). Development and use of an anti-zebra finch cannabinoid receptor type $1\left(\mathrm{CB}_{1}\right)$ antibody demonstrates distinct, dense cannabinoid receptor expression within song regions including Area X, IMAN (lateral magnocellular nucleus of anterior nidopallium), HVC, RA (robust nucleus of arcopallium), and L2. NCM receives L2 projections and is implicated in integration of auditory information. Activity in this area, determined through expression of the transcription factor ZENK, is increased after exposure to unfamiliar song. Because previous work has shown that these novel songstimulated increases in NCM activity are mitigated by cannabinoid exposure, we tested and found that similar effects on ZENK expression are produced by limiting food. Limited food-related reductions in the activity of NCM neurons were reversed by the cannabinoid antagonist SR141716A (N-piperidino-5-(4-chlorophenyl)-1-(2,4-dichlorophenyl)-4-methylpyrazole-3-carboxamide), implicating $\mathrm{CB}_{1}$ cannabinoid receptor involvement. Taken together, these experiments indicate a link between feeding state and gene expression related to auditory perception that is mediated by endocannabinoid signaling.
\end{abstract}

Key words: cannabinoid; feeding; auditory; $\mathrm{CB}_{1}$ receptor antibody; songbird; telencephalon

\section{Introduction}

Because songbirds learn a form of vocal communication in a manner with similarities to human language acquisition, they have become an important model for studying neurobiology underlying vocal development (Mooney, 1999). We have been using a songbird, the zebra finch, to study cannabinoid effects on vocal learning (Soderstrom and Johnson, 2000, 2001, 2003; Whitney et al., 2003). Cannabinoids are a structurally diverse group of compounds and the active constituents of marijuana. One of these compounds, $\Delta^{9}$-tetrahydrocannabinol, is responsible for most of the psychotropic actions of marijuana and acts mostly through cannabinoid receptors of type $1\left(\mathrm{CB}_{1}\right)$ in the brain. Endocannabinoids, including anandamide and 2-arachidonoylglycerol (2AG), are naturally occurring lipids capable of cannabinoid receptor activation (Di Marzo et al., 1998). Endocannabinoids produce diverse physiological effects ranging from peripheral modulation of immune function (Salzet et al., 2000; Di Marzo et

Received Dec. 16, 2003; revised Sept. 23, 2004; accepted Sept. 24, 2004.

This work was supported by National Institute on Drug Abuse Grant 1-R21-DA14693. We are grateful to Jackie McKeel for counting cells in $>300$ high-power fields, to Dr. Anton Reiner for help with avian neuroanatomy, and to Drs. David A. Taylor and Frank Johnson for reviewing this manuscript.

Correspondence should be addressed to Dr. Ken Soderstrom, Department of Pharmacology and Toxicology, Brody School of Medicine, East Carolina University, Greenville, NC 27834. E-mail: soderstromk@mail.ecu.edu. DOI:10.1523/JNEUROSCI.3298-04.2004

Copyright $\odot 2004$ Society for Neuroscience ～0270-6474/04/2410013-09\$15.00/0 al., 2004) to persistent changes in memory-related neuronal activity (Gerdeman and Lovinger, 2003). In humans, cannabinoids stimulate appetite and the intake of palatable food (Iversen, 2003), and accumulating evidence supports a relationship between cannabinoid signaling and feeding behavior (Di Marzo et al., 2001, 2004; Hanus et al., 2003; Matias et al., 2003; Matias and Di Marzo, 2004).

We found that cannabinoid treatment of adult male zebra finches, which express a $\mathrm{CB}_{1}$ receptor ortholog (Soderstrom and Johnson, 2000), decreases the amount that they sing (Soderstrom and Johnson, 2001). A similar inhibition of singing has recently been shown to occur as a function of brief periods of limited food access (Rashotte et al., 2001; Johnson and Rashotte, 2002). These similar effects (singing reductions) produced by dissimilar manipulations (cannabinoid exposure and limited food access) led us to investigate the possibility of a common mechanism. We report that decreased singing produced by limited food is partially reversed by pretreatment with the cannabinoid antagonist SR141716A [N-piperidino-5-(4-chlorophenyl)-1-(2,4-dichlorophenyl)-4-methylpyrazole-3-carboxamide (SR)], implicating endocannabinoid involvement. Endocannabinoid involvement is further demonstrated by the ability of brief periods of limited food access to increase levels of the endocannabinoid 2-AG in the caudal telencephalon.

Zebra finch caudal telencephalon contains the caudal medial 
nidopallium (NCM), a region implicated in the integration of auditory information (Chew et al., 1996). The NCM is a secondary auditory region that receives projections from the primary region L2 (subfield of L) (Vates et al., 1996). We now report that $\mathrm{L} 2$ is distinctly stained by antisera directed against the zebra finch $\mathrm{CB}_{1}$ cannabinoid receptor. Expression of the transcription factor ZENK within the NCM is stimulated by perception of novel song (Mello et al., 1995; Stripling et al., 1997). This type of immediateearly gene response may function as a persistent integrative signal important for processes related to learning and memory (Clayton, 2000). Novel song-stimulated ZENK expression within the $\mathrm{NCM}$ is selectively inhibited by exogenous cannabinoid pretreatment (Whitney et al., 2003). We show here that song-stimulated ZENK expression is also reduced by brief periods of limited food access. These reductions are cannabinoid antagonist reversible, implicating endocannabinoid involvement. Taken together, our results indicate that the feeding state and auditory perceptionrelated ZENK expression within the NCM are linked through endocannabinoid signaling.

\section{Materials and Methods}

Except where noted, all materials and reagents were purchased from Sigma (St. Louis, MO) or Fisher Scientific (Pittsburgh, PA). Immunochemicals were purchased from Vector Laboratories (Burlingame, CA). We have used the recently revised system of nomenclature in descriptions of zebra finch neuroanatomy (Reiner, 2004).

Animals. Adult male zebra finches ( $>90 \mathrm{~d}$ old) from domestic stock were used. Before the start of the experiment, birds were housed in flight aviaries with mixed seeds (SunSeed VitaFinch), grit, water, and cuttlebone available ad libitum. Each flight aviary contained several perches. The light/dark cycle was controlled at $14 / 10 \mathrm{hr}$, and the ambient temperature was maintained at $78^{\circ} \mathrm{F}$.

Limited food access. To generate tissue for endocannabinoid analysis, eight pairs of adult male zebra finches (16 animals total) were assigned randomly to limited food access (No Food) or ad libitum (Food) groups and housed in isolation in separate rooms with ad libitum access to food and water. One day after isolation, the food cups of No Food group animals were replaced with empty containers immediately before the beginning of the dark phase. Because these animals do not feed in the dark, differences in food access between Food and No Food animals began with the start of the following light phase. Restricted food access in the No Food group continued for a total of $4 \mathrm{hr}$. Immediately after this treatment period, birds were either anesthetized with Equithesin (Suzuki et al., 1996) and perfused transcardially before immunocytochemistry experiments or rapidly decapitated, with brain tissue dissected for lipid extraction (see below). Note that this brief period of food access, even when implemented for weeks, does not change body mass (Johnson and Rashotte, 2002).

For investigations of singing incidence, four adult males were moved to auditory recording chambers to habituate $7 \mathrm{~d}$ before the initiation of experiments and maintained on 14/10 hr light/dark cycles. Food was available ad libitum. After the habituation period, birds were given vehicle injections $30 \mathrm{~min}$ before the beginning of light cycles for three consecutive days. Singing incidence was recorded for $4 \mathrm{hr}$, and mean song bouts per hour were calculated over the $3 \mathrm{~d}$ of recording. After a $4 \mathrm{~d}$ recovery period, birds were again injected with vehicle for three consecutive days as above, and, in addition, food was removed. Singing was again recorded for $4 \mathrm{hr}$, food was replaced, and the overall mean song bout incidence was calculated (see Fig. 1, No Food). After a second $4 \mathrm{~d}$ recovery period with ad libitum food, birds were injected with $3 \mathrm{mg} / \mathrm{kg}$ of the cannabinoid antagonist SR141716A 30 min before lights-on, and food was removed. Birds were recorded as described above, and food was replaced after hour 4 of light cycles. Means over three consecutive days were calculated (see Fig. 1, SR + No Food). After a final $4 \mathrm{~d}$ recovery period with ad libitum food, birds were again injected with vehicle and recorded for $4 \mathrm{hr}$ for three consecutive days. These final vehicle injections were done to control for possible persistent effects of limited food and SR treatments. Significant differences were not detected (see Fig. 1, Post-Tx Food).

For ZENK immunocytochemistry experiments, a total of eight groups were used: (1) "No Food, No Song," a control group in which animals were not provided food for a $4 \mathrm{hr}$ period, as described above, and were not exposed to novel song stimulation $(n=2)$; (2) "SR, No Food, No Song," a second control group in which birds were treated as in No Food, No Song, except that they were injected with SR141716A (3 mg/kg, i.m.) $3 \mathrm{hr}$ into the light phase $(n=2)$; (3) "SR, Food, No Song," a third control group receiving SR141716A under ad libitum food conditions $(n=3)$; (4) "Food, No Song," a fourth control group in which animals received food ad libitum and were not exposed to a novel song $(n=4$; as detailed below); (5) "Food, Song," in which animals received food ad libitum and had activity within the NCM stimulated by exposure to a recording of novel song $(n=5)$; (6) "No Food, Song," in which animals were not provided food for a $4 \mathrm{hr}$ period, as described above, and had activity within the NCM stimulated by exposure to a recording of novel song $(n=7)$; (7) "SR, No Food, Song," in which animals were treated as in the No Food, Song group, except that they were injected with the $\mathrm{CB}_{1}$ cannabinoid receptor-selective antagonist SR141716A (3 mg/kg, i.m.) 30 min before song exposure ( $n=5)$; (8) "SR, Food, Song," in which birds received SR141716A under ad libitum food conditions $(n=3)$.

Analysis of zebra finch brain endocannabinoid content. Fourteen adult male zebra finches were assigned randomly to control or limited food access groups ( $n=7$ animals per treatment). Limited food access was administered as described above. Brains were removed, blocked down the midline, and tissue from each half was extracted and analyzed independently resulting in two data points per sample per bird, with a final $n=14$ per treatment. Tissue from each brain half was rapidly dissected into rostral [containing the song regions IMAN (lateral magnocellular nucleus of anterior nidopallium) and Area X] and caudal [containing the song regions HVC and RA (robust nucleus of arcopallium) and auditory regions L2 and NCM] telencephalon, cerebellum, and midbrain and immediately frozen in liquid nitrogen. Frozen tissue was stored at $-80^{\circ} \mathrm{C}$ until extracted, as described previously (Matias et al., 2003). Briefly, tissues were homogenized in and extracted with $50 \mathrm{~mm}$ chloroform: methanol:Tris- $\mathrm{HCl}, \mathrm{pH} 7.5[2: 1: 1(\mathrm{v} / \mathrm{v})]$ containing internal standards (10 pmol of $\left[{ }^{2} \mathrm{H}\right]_{8}$ anandamide, $\left[{ }^{2} \mathrm{H}\right]_{4} N$-palmitoylethanolamine, and 100 pmol of $\left[{ }^{2} \mathrm{H}\right]_{5}$-2-arachidonyl glycerol; obtained from Cayman Chemical, Ann Arbor, MI). The lipid-containing organic phase was collected and dried. The mass of dried extract was determined and prepurified by open-bed chromatography on silica gel. Fractions eluted with 9:1 chloroform:methanol were analyzed by liquid chromatographyatmospheric pressure chemical ionization-mass spectrometry (LCAPCI-MS) using a Shimadzu HPLC apparatus (LC-APCI-MS) coupled with a LCMS-2010 quadruple MS via an APCI interface (both from Shimadzu). MS analyses were performed in the selected ion monitoring, as described previously (Di Marzo et al., 2000). The temperature of the APCI source was $400^{\circ} \mathrm{C}$, and the HPLC column was a Phenomenex (5 $\mathrm{mm}, 150 \times 4.5 \mathrm{~mm}$ ) reverse-phase column, eluted as described previously (Di Marzo et al., 2000). Anandamide (retention time, $13.5 \mathrm{~min}$ ), $\mathrm{N}$-palmitoylethanolamine (retention time, $17.5 \mathrm{~min}$ ), and 2-AG (retention time, $15.0 \mathrm{~min}$ ) quasi-molecular ions $(\mathrm{m} / \mathrm{z}=348.0,300.0$, and 379.3) were quantified by isotope dilution with the above-mentioned deuterated standards (same retention times and $\mathrm{m} / \mathrm{z}=356.0,304.0$, and 384.3), and their amounts in picomoles or nanomoles were normalized per milligram of lipid extract. Two LC-MS peaks for both deuterated and undeuterated mono-arachidonoylglycerol were found at retention times of 15.0 and $16.9 \mathrm{~min}$, respectively, corresponding to $2-\mathrm{AG}$ and 1(3)-AG, in agreement with the previous observation that 2-AG undergoes isomerization during the purification procedure (Di Marzo et al., 1999). Therefore, the amounts of 2-AG were calculated by adding the amounts of the two isomers.

Silica column fractions eluted with 1:1 chloroform:methanol, which contain the $\mathrm{N}$-acylphosphatidylethanolamines, were processed with Streptomyces chromofuscus phospholipase D to yield the corresponding $\mathrm{N}$-acylethanolamines in a quantitative manner, as described previously (Di Marzo et al., 2001). Therefore, the anandamide biosynthetic precursor $\mathrm{N}$-arachidonoyl-phosphatidylethanolamine was quantified by quan- 
tifying, by means of LC-APCI-MS, the anandamide produced from its hydrolysis by the phospholipase $\mathrm{D}$.

Induction of ZENK expression within NCM. Increased expression of the immediate-early gene ZENK within the NCM was produced using an established protocol (Mello and Ribeiro, 1998). Three hours, 30 min into the light phase, a digital recording of a novel zebra finch song consisting of three bouts of $\sim 5 \mathrm{sec}$ each, followed by $45 \mathrm{sec}$ of silence, was played 30 times. This procedure results in increased ZENK expression selectively within the NCM. Note that novel song-stimulated ZENK expression is inhibited by pretreatment with the cannabinoid agonist WIN55212-2 $(R(+)-$ [2,3-dihydro-5-methyl-3-([morpholinyl] methyl)pyrrolo(1,2,3-de)-1,4benzoxazin-yl]-(1-naphthalenyl)methanone) in an antagonist-reversible manner, clearly demonstrating $\mathrm{CB}_{1}$ receptor involvement (Whitney et al., 2003). Thirty minutes after the end of song stimulation, birds were overdosed with Equithesin and perfused transcardially for preparation of brain tissue for ZENK immunohistochemistry experiments described below.

Cannabinoid antagonist administration. The $\mathrm{CB}_{1}$ receptor-selective antagonist SR141716A (Pertwee, 1999) was obtained from the Research Triangle Institute (Raleigh, NC) through the National Institute on Drug Abuse program. Akamuls was a gift from Rhodia (Cranberry, NJ). Stocks of SR141716A (20 mM) were prepared in DMSO and stored at $-80^{\circ} \mathrm{C}$ until diluted for injection. Dilutions were made to produce a suspension of DMSO:Alkamuls:PBS (1:1:18). The concentration of SR141716A was adjusted to deliver $3 \mathrm{mg} / \mathrm{kg}$ in a volume of $50 \mu \mathrm{l}$. Treatments were given 30 min before initiation of song exposure (see above) by intramuscular injection into the large pectoralis flight muscle.

Anti-zebra finch $C B_{1}$ cannabinoid receptor immunocytochemistry. Previous molecular cloning of $\mathrm{cDNA}$ encoding the zebra finch $\mathrm{CB}_{1}$ cannabinoid receptor (Soderstrom and Johnson, 2001) has allowed us to produce a species-specific polyclonal antibody with Spring Valley Laboratories (Woodbine, MD). We have targeted a 16-amino acid region within the intracellular tail portion of the zebra finch $\mathrm{CB}_{1}$ cannabinoid receptor: HAFRSMFPTSEGTAQP-C-OH. This sequence encompasses His 408 to Pro 423 . Cys 417 was changed to a Ser residue (Ser shares the same physicochemical properties of Cys, and replacement of Cys minimizes complications attributable to oxidation). The predicted epitope is FRSMFP. The antisera were produced in rabbit. The immunochemical specificity of these antisera is demonstrated by the absence of staining after preincubation with $20 \mu \mathrm{M}$ of the immunizing peptide (see Fig. 4, compare $A, B$ ). Western blotting indicates staining of bands with molecular weights consistent with isoforms of zebra finch $\mathrm{CB}_{1}$ (see Fig. 3). Masses of these isoforms are similar to those reported by Egertova and Elphick (2000) and Wager-Miller et al. (2002) and may represent products of alternate splicing, glycosylation, and receptor dimerization. For immunohistochemistry experiments, $30 \mu \mathrm{m}$ sections of adult male zebra finch medial telencephalon were reacted with affinity-purified anti-zebra finch $\mathrm{CB}_{1}$ antibody (1:3000), as described below for ZENK, except that an HRP-conjugated anti-rabbit antibody was used in place of avidinbiotin-peroxidase complex.

ZENK immunocytochemistry. Polyclonal anti-Egr-1 antibody was purchased from Santa Cruz Biotechnology (catalog \#C-19; Santa Cruz, CA). The specificity of the interaction of this reagent with zebra finch ZENK has been well established (Mello and Ribeiro, 1998). Other reagents were purchased from Vector Laboratories. As indicated above, birds were killed by Equithesin overdose and perfused transcardially with phosphate-buffered $4 \%$ paraformaldehyde, $\mathrm{pH}$ 7.0. After brains were removed and immersed overnight in $4 \%$ paraformaldehyde, the left telencephalic hemisphere was blocked at its lateral edge and sectioned parasagitally (medial to lateral) at $30 \mu \mathrm{m}$ on a vibrating microtome. ZENK immuocytochemistry was performed using a standard protocol reported by Whitney et al. (2000). Briefly, tissue sections were rinsed in $0.1 \% \mathrm{H}_{2} \mathrm{O}_{2}$ for $30 \mathrm{~min}$, blocked with $5 \%$ goat serum for $30 \mathrm{~min}$, and incubated overnight in blocking solution containing anti-Egr- 1 antibody (1:1000). After antibody exposure, sections were rinsed in saline, incubated in blocking solution containing biotinylated anti-rabbit solution (1:500) for $1 \mathrm{hr}$, rinsed with PBS again, and then submerged in avidinbiotin-peroxidase complex solution for $1 \mathrm{hr}$. Antibody labeling was visualized with DAB solution. Control sections that were not incubated in primary antibody were not immunoreactive.

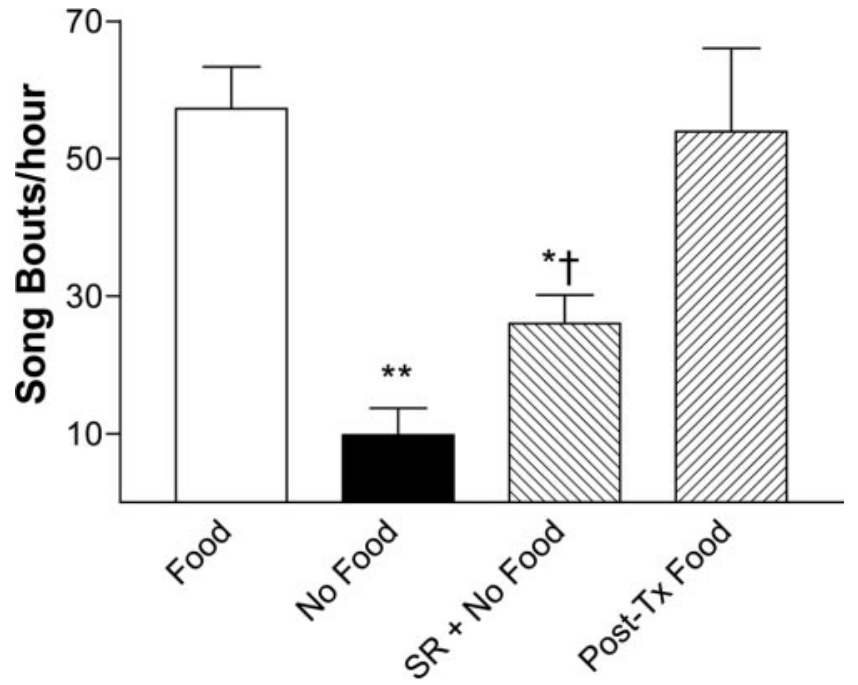

Figure 1. Limited food availability reduces singing, an effect partially reversed by the cannabinoid antagonist SR141716A (SR). The methods described by Rashotte et al. (2001) were adapted. Food was limited for the first $4 \mathrm{hr}$ of $14 \mathrm{hr}$ light cycles. Song bout incidence was recorded over the $4 \mathrm{hr}$ without food. Food was provided at the end of recording sessions. Three sessions were recorded on successive days, followed by $72 \mathrm{hr}$ of ad libitum food access between treatments. Data for all three recording days were pooled before analysis. Shown are means \pm SEM of total number of song bouts recorded $(n=4)$. Relationships between treatment and mean song bouts per hour produced were assessed with one-way ANOVA followed by SNK post-tests. ${ }^{*} p<0.001$, difference from Food control; ${ }^{\dagger} p<0.001$, difference from № Food group. The partial nature of SR reversal may indicate that the dosage ( $3 \mathrm{mg} / \mathrm{kg}$ ) was submaximally effective (higher dosages were impractical). Cannabinoid antagonist reversal is consistent with endocannabinoid involvement. These behavioral results are in good agreement with limited food-related increased brain endocannabinoid levels (see Fig. 2).

Data analysis and statistics. Data analyses and statistical procedures were performed using Prism GraphPad, SigmaStat, and Microsoft Excel personal computer software. All quantification procedures on individual birds were completed without knowledge of the experimental group. The density of ZENK-immunolabeled cells was measured using previously established procedures (Whitney et al., 2000). Immunoreactive nuclei within the NCM was the unit of count within a high-power grid defined by $60 \times$ objective (volume, $0.0009 \mathrm{~mm}^{3}$ ). As described by Mello and Ribeiro (1998), an inclusive counting criterion was used (all lightly and darkly stained cells were counted). For each bird, three randomly selected high-power fields were counted per NCM in four different tissue sections. High-power fields were counted independently by two persons blind to treatment. These duplicate counts were pooled for analysis. The density of ZENK-labeled cells was defined as the total number of immunoreactive cells counted divided by the volume of the 12 high-power fields. Parasagittal sections of the caudal telencephalon $\sim 0.15 \mathrm{~mm}$ from midline were used to quantify NCM ZENK induction. Previous studies show that in this region robust uniform levels of song-induced ZENK expression occurs within clearly defined boundaries of the NCM (Mello and Clayton, 1994; Mello and Ribeiro, 1998; Whitney et al., 2003). ZENK expression data are reported as mean labeled cells per cubed millimeter of $\mathrm{NCM} \pm \mathrm{SEM}$. Differences between treatment and control groups were evaluated by one-way ANOVA. Between-group differences in the number of ZENK-expressing cells in the NCM were assessed with the Student-Newman-Keuls (SNK) test. Differences in anandamide and 2-AG content across groups and brain regions were assessed with two-factor ANOVA, followed by SNK post-tests.

\section{Results}

\section{Cannabinoid antagonist reversal of food-related reductions in singing}

Results reported in Figure 1 confirm previous reports of decreased incidence of song bouts related to brief periods of limited 
food availability (Rashotte et al., 2001). However, we have now found that this effect is partially reversed by pretreatment with the $\mathrm{CB}_{1}$ receptor-selective antagonist SR141716A. Antagonist reversal supports involvement of endocannabinoid signaling in limited food-related decreased singing. The partial nature of this reversal suggests that the $3 \mathrm{mg} / \mathrm{kg}$ SR141716A dosage may not have been maximally effective and is consistent with the distinctly loweraffinity interaction of SR141716A with zebra finch $\mathrm{CB}_{1}$ relative to mammalian orthologs (Soderstrom and Johnson, 2001). Use of higher dosages (e.g., $10 \mathrm{mg} / \mathrm{kg}$ ) was impractical because of difficulties producing an even suspension for injection in 50 $\mu l$.

\section{Analysis of zebra finch brain endocannabinoid content}

All regions of Zebra finch brain were found to contain the two endocannabinoids anandamide and 2-AG (Fig. 2), as well as the anandamide precursor $\mathrm{N}$ arachidonoylphosphatidylethanolamine, in levels 10- to 15-fold higher than anandamide (data not shown). These data provide unprecedented evidence for the presence of a complete endocannabinoid system in a bird species. There were significant main effects of brain region for both 2-AG and anandamide measures ( $F=4.97$ and 9.33, respectively; $p<0.01$ in each case), indicating significant differences in endocannabinoid content across the distinct brain regions studied. A significant main effect for food availability was found for $2-\mathrm{AG}(F=14.05 ; p<0.01)$ but not anandamide $(F<1)$. Post-tests revealed significant limited food-related increases in 2-AG for rostral and caudal telencephalon and midbrain $(p<0.05$ in each case), but not cerebellum $(p=0.85)$. As in mammals, the tissue concentrations of 2-AG were up to 500-fold higher than those of anandamide and were highest in the caudal telencephalon, which includes both L2 and NCM.

\section{Pattern of anti-zebra finch $\mathrm{CB}_{1}$} antibody staining in telencephalon Specificity of the anti-zebra finch $\mathrm{CB}_{1}$ antibody was demonstrated through Western blotting (Fig. 3) and by elimination of distinct staining after preincubation with $20 \mu \mathrm{M}$ of the immunizing peptide (Fig. 4, compare $A, B$ ). Within the caudal telencephalon, staining indicates distinct $\mathrm{CB}_{1}$ receptor expression within a stripe of the rostral hyperpallium, the rostral tip of nidopallium, a portion of the caudal hippocampus, and throughout L2, which, importantly, projects to NCM (Fig. 4C). Some expression is evident within the NCM, but at levels low relative to that within L2.
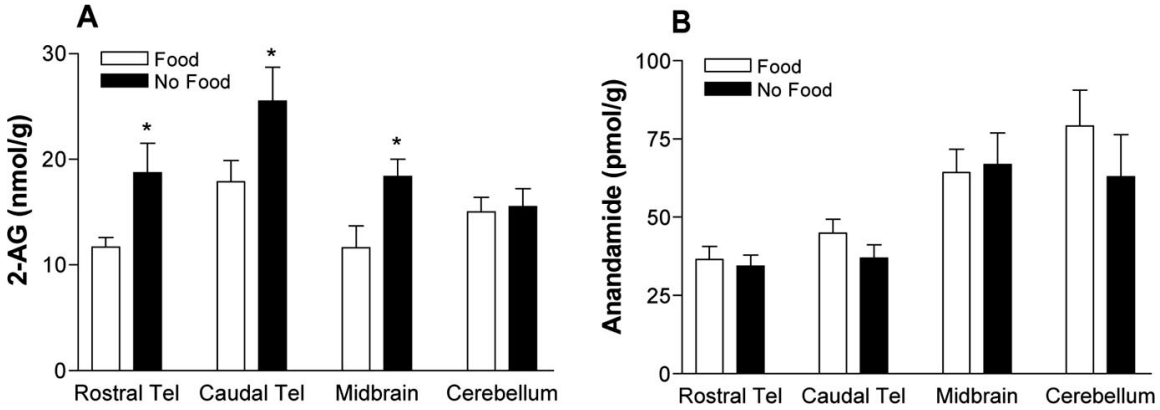

Figure 2. Effect of food access on endogenous cannabinoid levels in zebra finch brain. Animals were either provided food ad libitum (Food) or subjected to $4 \mathrm{hr}$ of limited food access (No Food), as described in Materials and Methods. Brains were rapidly dissected into rostral (Rostral Tel) and caudal (Caudal Tel) telencephalon, midbrain, and cerebellum. Lipids were extracted, spiked with deuterium-labeled internal standards, and subjected to LC-APCI-MS for quantitative analysis of 2-AG $(A)$ and anandamide $(B)$ content. ANOVA indicates a significant relationship between brain region and anandamide content $(p<0.05)$. Post hoc analysis reveals a significant increase in 2-AG content in the midbrain and rostral and caudal telencephalon (which contains auditory regions $\mathrm{L} 2$ and $\mathrm{NCM})$ of animals subjected to limited food access $\left({ }^{*} p<0.05\right)$.

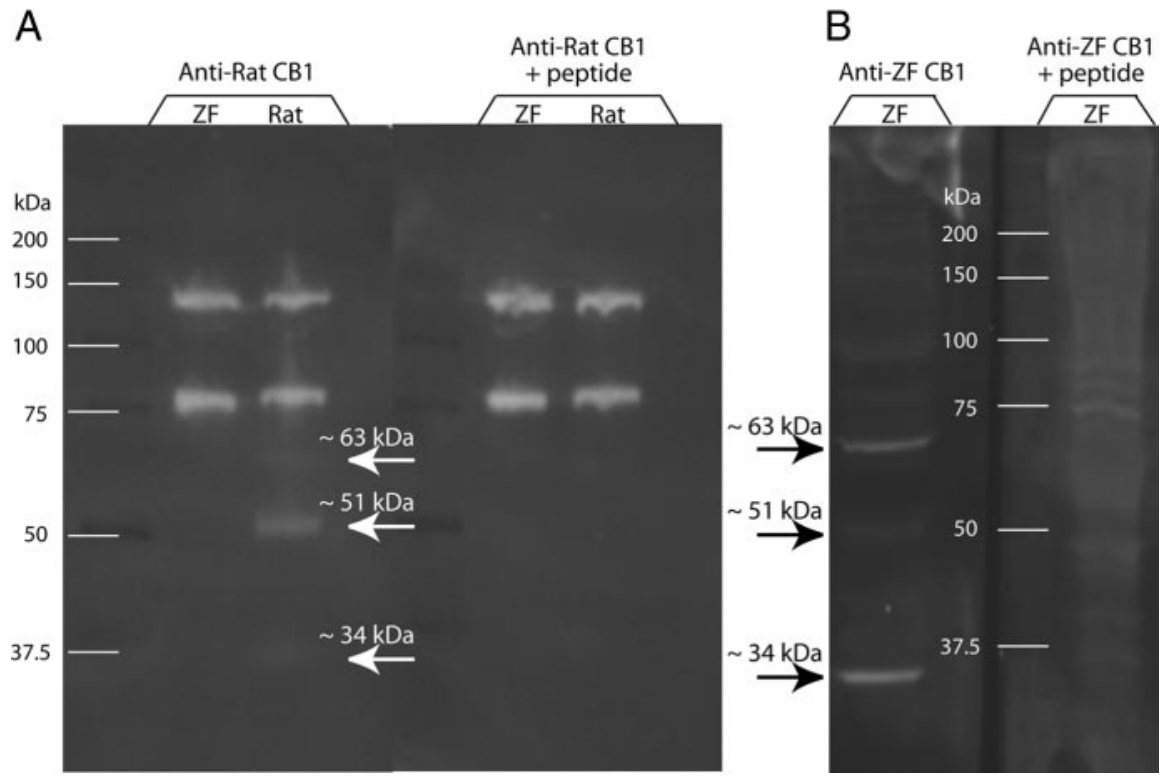

Figure 3. Specificity of anti- $\mathrm{CB}_{1}$ antibody labeling investigated through Western blotting. Comparison of Western blot results obtained with anti-rat and anti-zebra finch $\mathrm{CB}_{1}$ cannabinoid receptor antibodies is shown. Zebra finch whole-brain (ZF) and rat cerebellar homogenates (30 $\mu \mathrm{g}$ of protein each) were separated by 10\% SDS-PAGE and blotted to nitrocellulose. The anti-rat antibody was generously provided by $\mathrm{Dr}$. M. Elphick and is directed against the C-terminal, intracellular tail region of $\mathrm{CB}_{1}$. The zebra finch anti-CB antibody is also directed against the intracellular tail domain. $A$, Left, Staining of zebra finch (ZF) and rat brain protein with anti-rat $\mathrm{CB}_{1}$ antibody (1:8000). The two intense, high-molecular weight bands present in all blots (79.6 and $\left.133 \mathrm{kDa}\right)$ represent artifactual labeling of biotin-containing proteins by the streptavidin-alkaline phosphatase detection reagent used. These bands serve as an excellent loading control. Rat lane bands of $\sim 63.5,50.4$, and $34.7 \mathrm{kDa}$ correspond to isoforms of $C B_{1}$ as reported by Egertova and Elphick (2000). Note the lack of labeling of zebra finch proteins with the rat reagent. Right, Antibody labeling of rat $\mathrm{CB}_{1}$ isoforms is blocked by preincubation with $10 \mu \mathrm{g}$ of the immunizing peptide. $B$, Labeling of zebra finch whole-brain protein with anti-zebra finch $C_{1}$ antibody (1:3000). A direct anti-rabbit peroxidase conjugate was used for detection avoiding streptavidin artifacts. Left, Labeling of zebra finch proteins corresponding in size to rat $C_{1}$ isoforms (compare with $A$ ). Notably, the $\sim 51 \mathrm{kDa}$ isoform is either labeled less intensely by the zebra finch reagent or is less abundantly expressed within whole zebra finch brain relative to rat cerebellum. Right, Staining of zebra finch $\mathrm{CB}_{1}$ isoforms is eliminated by preincubation with $20 \mu \mathrm{m}$ of the immunizing peptide.

Staining of more lateral sections (Fig. $4 D, E$ ) demonstrate $\mathrm{CB}_{1}$ receptor expression in song control regions important for vocal learning (Area X and IMAN) and motor production (HVC and RA). Diffuse staining throughout the globus pallidus is consistent with distribution of $\mathrm{CB}_{1}$ receptor expression in mammalian species (Egertova and Elphick, 2000). Other regions of distinct expression include a distinct region of the hyperpallium and nucleus taeniae of the amygdala. 

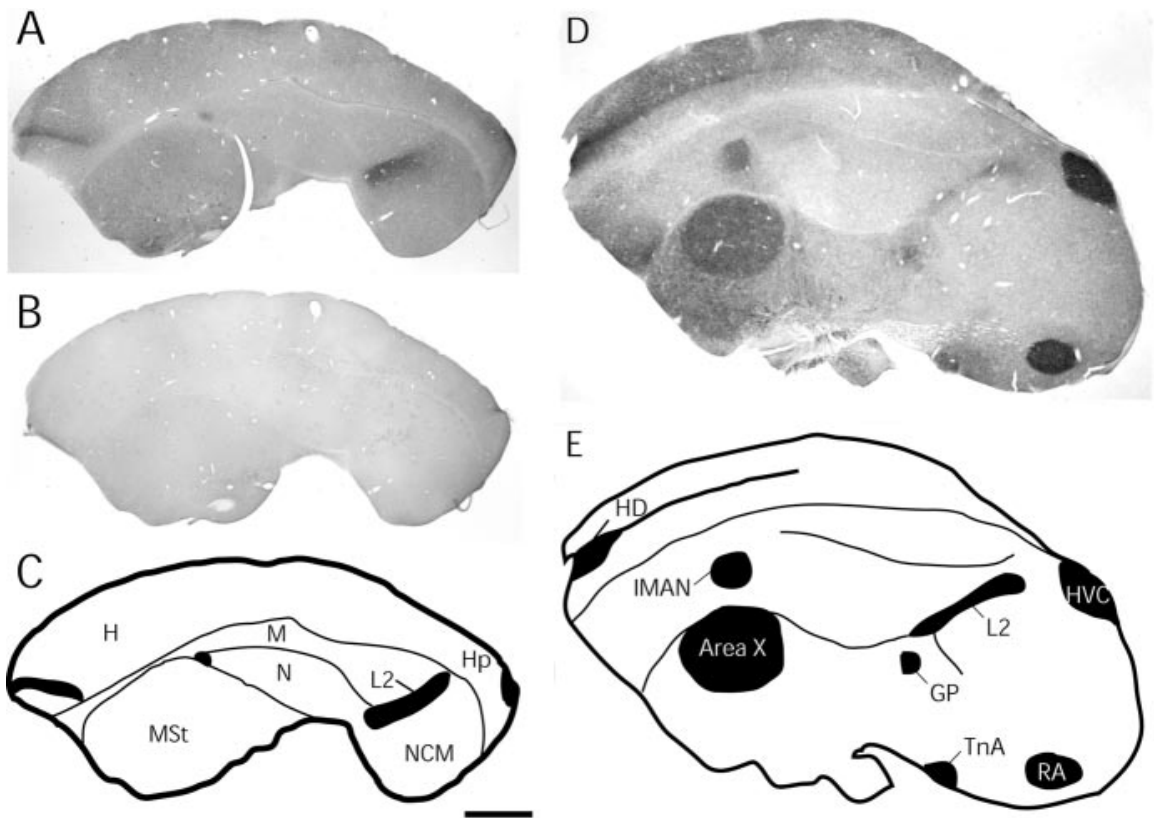

Figure 4. Immunohistochemical staining of zebra finch telencephalon with anti-zebra finch $\mathrm{CB}_{1}$ receptor antibody. $A-C$, Medial parasagittal sections represent planes $\sim 0.15 \mathrm{~mm}$ lateral from the midline. $D, E$, More lateral parasagittal sections represent planes $\sim 1 \mathrm{~mm}$ from the midline. Rostral is left. Scale bar, $1 \mathrm{~mm}$. Thirty-micrometer sections were incubated with affinitypurified primary antibody (1:3000), followed by HRP-conjugated secondary antibody and DAB staining. A, D, Staining produced with anti-zebra finch $\mathrm{CB}_{1}$ receptor antibody. $A$, Note distinct staining within $L 2$ that projects to $\mathrm{NCM}$, of a stripe within the rostral hyperpallium $(\mathrm{H})$, the rostral tip of nidopallium $(\mathrm{N})$, and in caudal hippocampus $(\mathrm{Hp})$. Diffuse staining throughout the medial striatum (MSt) is consistent with distribution of $\mathrm{CB}_{1}$ receptor expression in mammalian species. $B$, Distinct staining is eliminated by preincubation of the antibody with $20 \mathrm{~mm}$ of the immunizing peptide. C, Camera lucida drawing indicates location of regions within the medial telencephalon. Black shading corresponds to distinct anti-zebra finch $\mathrm{CB}_{1}$ receptor staining. $M$, Mesopallium. $D$, Distinct $C_{1}$ receptor expression within the telencephalon. Note distinct staining of song regions including IMAN, Area X, L2, HVC, and RA. Additional regions with distinct labeling include a distinct region of the hyperpallium (HD), nucleus taeniae of the amygdala (TnA), and globus pallidus (GP). E, Camera lucida drawing indicates regions of distinct staining.

Higher-power images of staining in selected regions (Fig. 5) demonstrates distinct labeling of small $(<10 \mu \mathrm{m})$ somata and negative labeling of larger cell types. Distinct staining of brain regions evident in Figure 4 (e.g., Area X, IMAN, L2, HVC, RA) is associated with (1) particularly intense labeling of small somata relative to other regions and (2) distinct labeling of neuropil (compare $600 \times$ L2, HVC, and RA with NCM).

\section{Effects of limited food access on song-stimulated neural activity within NCM}

There was a significant relationship between treatment group and the density of ZENK-expressing cells in the NCM (ANOVA, $p<$ 0.001 ) (Figs. 6, 7). Post hoc analysis revealed that ZENK expression was increased with exposure to novel song in both control animals and those subjected to periods of limited food access (Fig. 7) (asterisk indicates significant difference from Food, No Song group with mean ZENK-expressing cells in the NCM: $21134 \pm 3567 / \mathrm{mm}^{3} ; p<0.05$ in all cases, SNK). However, in the limited food access group, these increases were to levels significantly lower than controls (Fig. 7) (dagger indicates mean ZENKexpressing cells within the NCM: $78276 \pm 8803$ in the Food, Song group vs $36601 \pm 3203 / \mathrm{mm}^{3}$ in the No Food, Song group; $p<$ $0.001, \mathrm{SNK})$. The lower level of novel song-stimulated ZENK expression in animals subjected to limited food access was reversed by pretreatment with the $\mathrm{CB}_{1}$ receptor-selective antagonist SR141716A (3 mg/kg, i.m.) (Fig. 7) (double dagger indicates mean ZENK-expressing cells within the NCM of the SR, No Food, Song group: $64972 \pm 9109 / \mathrm{mm}^{3}$ ). Low numbers of ZENK- expressing cells were observed in each of the three No Song control groups, and these numbers did not significantly differ across the controls. The inability of the SR141716A antagonist to enhance novel song-stimulated ZENK expression (compare the Food, Song and SR, Food, Song groups) is consistent with either (1) maximal activation of ZENK expression under the conditions used or (2) lack of basal inhibitory endocannabinoid tone.

\section{Discussion}

Our results demonstrate that brief periods of limited food availability increase the levels of the endocannabinoid 2-AG in zebra finch brain. At the same time, limited food availability decreases song-induced expression of the immediate-early gene ZENK within the NCM, a region important for integration of auditory information (Mello and Ribeiro, 1998). Because food-related decreases in NCM activity were reversed by pretreatment with the cannabinoid antagonist SR141716A, we suggest that this effect is attributable to increased endocannabinoid signaling via $\mathrm{CB}_{1}$ receptors. This suggestion was confirmed by the finding of elevated $2-A G$, but not anandamide, levels in the caudal telencephalon, which contains the NCM. It is not unusual for the two major endocannabinoids to be differentially regulated during physiological and pathological conditions (for examples, see Giuffrida et al., 1999; Di Marzo et al., 2000; Marsicano et al., 2003; Valenti et al., 2004). This phenomenon is attributable to distinct enzymes underlying biosynthetic and metabolic processes for anandamide and 2-AG (Di Marzo et al., 1998), and these enzymes are likely subject to differential regulation by physiological stimuli.

Increased 2-AG levels were also found in two other brain regions of zebra finches subjected to limited food access, the rostral telecephalon and the midbrain, but not the cerebellum, and are consistent with elevated 2-AG levels in the limbic forebrain and hypothalamus, but not the cerebellum, of fasting rats (Kirkham et al., 2002). It is becoming clear that cannabinoid signaling is an important mediator of ingestive behavior (Berger et al., 2001; Berry and Mechoulam, 2002). For example, $\mathrm{CB}_{1}$ receptordeficient mice are leaner than controls (Cota et al., 2003). In humans, $\mathrm{CB}_{1}$ cannabinoid receptor activation increases appetite, and the $\mathrm{CB}_{1}$-selective antagonist SR141716A exhibits hypophagic efficacy (Iversen, 2003). A part of endocannabinoid effects on ingestive behavior appears to be under the control of the leptin signaling system, which reduces endocannabinoid levels in mouse hypothalamus and is associated with elevated endocannabinoid levels in hypothalami of genetically obese, leptindeficient rodents (Di Marzo et al., 2001). The endocannabinoid system is also involved in reinforcing the incentive value of food, as demonstrated by the finding that, under certain conditions, SR141716A inhibits the intake of palatable food selectively versus normal food (Higgs et al., 2003). In this case, endocannabinoids seem to act mostly in the limbic forebrain and more particularly 
in the nucleus accumbens, possibly to stimulate dopamine release from terminals of neurons originating in the ventral tegmental area. This is supported by demonstration that infusion of 2-AG directly into the nucleus accumbens shell dose dependently stimulates feeding (Kirkham et al., 2002).

Elevated 2-AG levels after short periods without food are now well documented in rat and mouse brain (Kirkham et al., 2002; Hanus et al., 2003). Interestingly, longer, perhaps starvation-relevant, periods of dietary restriction produce significant decreases in 2-AG levels (Hanus et al., 2003). This may reflect a beneficial adaptation to extended periods of food shortage, mitigating behavior-altering, and as our results indicate, perception-altering endocannabinoid effects that may distract from other important activities during difficult times. It will be important to determine whether similarly extended periods of food restriction will reduce brain 2-AG in our avian model. Our current results suggest that such reductions should augment auditory perception-related ZENK responsiveness in the NCM.

Insight into brain regions involved in endocannabinoid regulation of NCM activity has been gained through development of a species-specific anti-zebra finch $\mathrm{CB}_{1}$ antibody. We were generously provided anti-rat $\mathrm{CB}_{1}$ receptor antibodies by Dr. Maurice Elphick (Queen Mary College of London, London, UK) and Dr. Ken Mackie (University of Washington, Seattle, WA) but could not demonstrate specific interaction of these reagents with the avian receptor, likely because of a combination of reduced affinity for zebra finch $\mathrm{CB}_{1}$ and increased nonspecific interactions with avian proteins (Fig. 3). Specificity of the new anti-zebra finch $\mathrm{CB}_{1}$ antibody is supported by the following: (1) elimination of staining after preincubation with $20 \mu \mathrm{M}$ of the immunizing peptide (Fig. 4, compare $A, B$ ); (2) Western blotting results demonstrating interaction with isoforms consistent in mass with those labeled by well established anti-rat reagents (Fig. 3) and; (3) consistency of the pattern of antibody labeling with that ob-

served previously with cDNA probes directed to $\mathrm{CB}_{1}$ mRNA within the caudal telencephalon (Soderstrom and Johnson, 2000). The distinct neuropil staining and negative staining of large neurons within distinct regions of the telencephalon obtained with the anti-zebra finch $\mathrm{CB}_{1}$ antibody is consistent with the staining patterns obtained in rat brain using antibodies directed against both $\mathrm{N}$-terminal (Tsou et al., 1998) and C-terminal (Egertova and Elphick, 2000) regions of the rat $\mathrm{CB}_{1}$ receptor. Distinct staining of somata was not observed in rat brain with the C-terminal-directed antibody, and therefore our reagent (which
$200 X$
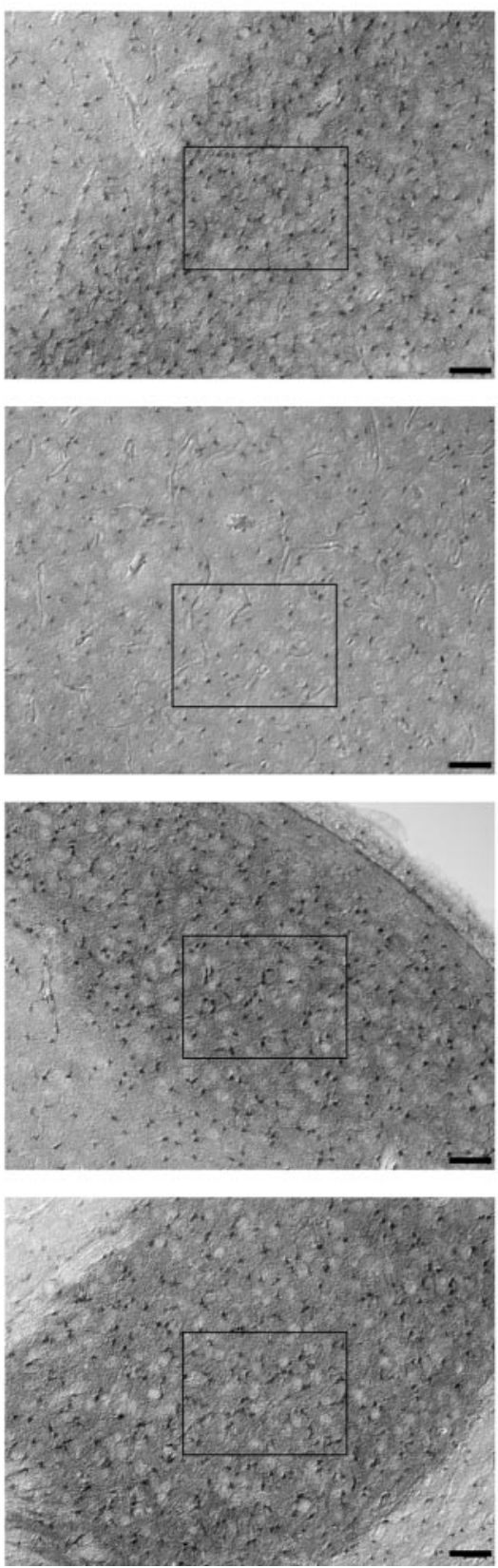

$600 x$
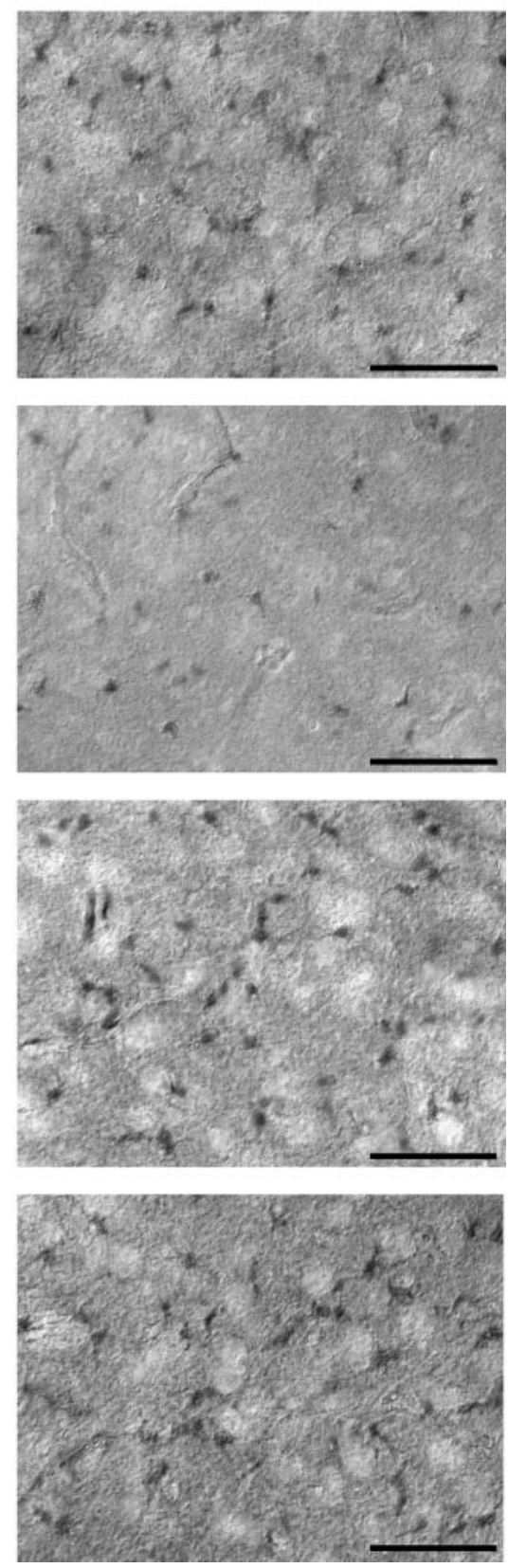

Figure 5. Higher-power images of anti-zebra finch $\mathrm{CB}_{1}$ antibody staining in selected telencephalic regions. Thirty-micrometer parasagittal sections were incubated with affinity-purified primary antibody (1:3000), followed by HRP-conjugated secondary antibody and DAB staining. Scale bars, $50 \mu \mathrm{m}$. The boxes in $200 \times$ images indicate the location of corresponding $600 \times$ images. Intense staining of small somata and fibroid processes within L2, HVC, and RA contrast with less-intense labeling within the NCM. Intense staining within the song regions HVC and RA is consistent with distinct, high-level expression of mRNA encoding zebra finch $C_{1}$ receptors reported previously (Soderstrom and Johnson, 2000).

is directed against a more proximal region of the C-terminal tail domain of $\mathrm{CB}_{1}$ ) shares more similarity in staining pattern with the N-terminal-directed rat reagent. These similarities further extend to intense interaction with proteins of $\sim 63 \mathrm{kDa}$ on Western blots (Fig. 3) (Tsou et al., 1998, compare their Fig. 1A), suggesting that this isoform may be that associated with somal expression.

Availability of this anti-zebra finch $\mathrm{CB}_{1}$ antibody will facilitate determination of the pattern of cannabinoid receptor expression within avian CNS and during the distinct stages of late postnatal 

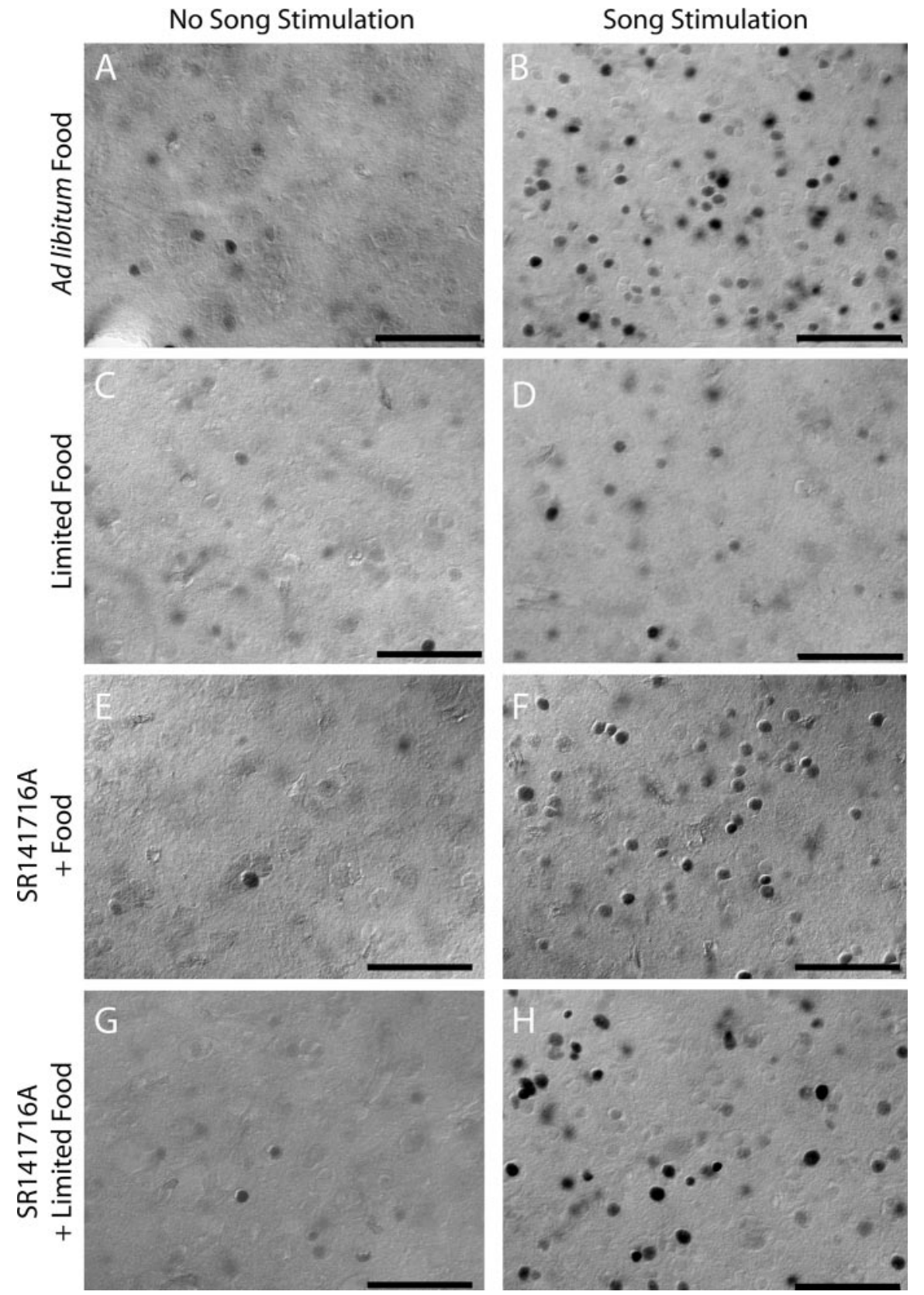

Figure 6. Example photomicrographs of anti-ZENK immunocytochemical staining within zebra finch NCM. Scale bars, $50 \mu \mathrm{m}$. Without novel song stimulation, ZENK expression was low across all food conditions $(A, C, E, G)$. With ad libitum food access, novel song stimulation increased ZENK expression (compare $A, B$ ). Song-stimulated increased ZENK expression was to lower levels during limited food access (compare $B, D$ ). Limited food-associated decreased ZENK expression was reversed by the $C_{1}$-selective antagonist SR141716A, implicating endocannabinoid involvement ( $3 \mathrm{mg} / \mathrm{kg}$, i.m., given $30 \mathrm{~min}$ before song exposure; $D, H$ ). SR141716A did not augment song-stimulated ZENK expression (F).

development when zebra finch vocal learning occurs. These experiments are currently underway. Immunochemical results already obtained support distinct, high-level $\mathrm{CB}_{1}$ expression in brain regions important for vocal learning (Area $\mathrm{X}$ and lMAN) and production (HVC and RA) (Fig. 4). These results confirm and extend our previous finding of distinct, high-level $\mathrm{CB}_{1}$ mRNA expression within HVC and RA (Soderstrom and Johnson, 2000) and provide insight into brain regions likely to be involved in cannabinoid-altered vocal learning (Soderstrom and Johnson, 2003).

The dense anti- $\mathrm{CB}_{1}$ labeling within $\mathrm{L} 2$ suggests a possible lo- cation for food-related changes in endocannabinoid signaling (Fig. 2). L2 is the primary recipient of thalamic auditory input and is characterized electrophysiologically by simple tone responses (Bonke et al., 1979). L2 projects to L1, L3, and the $\mathrm{NCM}$, and these secondary auditory regions are characterized by increased response selectivity consistent with integration of auditory information (Muller and Scheich, 1987). Within L1 and L3, neurons are more likely to depolarize in response to complex sounds than to simple tones (Muller and Scheich, 1988). In the case of zebra finch NCM, activity evidenced by ZENK expression is selectively elicited by exposure to novel song patterns indicating a high degree of integration (Mello et al., 1995). Because complex sound selectivity in other secondary auditory regions (L1 and L3) is dependent on GABAergic signaling at the level of L2 (Muller and Scheich, 1987), it is possible that similar integrative responsiveness within NCM is also dependent on L2 GABAergic activity. The high density of $\mathrm{CB}_{1}$ receptors within $\mathrm{L} 2$ raises the possibility that their activation may disrupt this signaling through mechanisms similar to $\mathrm{CB}_{1}$ inhibition of GABA release in rat hippocampus and the nucleus accumbens (Hoffman and Lupica, 2000, 2001). Additional electrophysiological experiments will be required to understand the circuitry involved in the effects that we have measured. The well studied, tonotopic anatomy of the avian auditory telencephalon will facilitate these experiments.

Our results extend previous work demonstrating that exogenously administered cannabinoids reduce song perceptionrelated ZENK expression (Whitney et al., 2003) and demonstrate for the first time endocannabinoid mediation of processes related to integration of auditory information. These results also indicate a relationship between auditory perception and feeding state.

The ZENK expression that we have studied has been characterized as part of a "genomic action potential," wherein integrative neurons receive suprathreshold activation and respond through immediateearly gene expression rather than, or in addition to, depolarization (Clayton, 2000). Products of immediate-early genes such as ZENK are transcription factors capable of altering patterns of gene expression. Such changes in gene expression patterns are responsible for persistent physiological changes, making them candidates for involvement in processes related to learning and memory. For example, ZENK expression is enhanced with production of long-term potentiation of synaptic activity in rat hippocampus (Cole et al., 1989). In our zebra finch system, because ZENK expression within the NCM only occurs in response to unfamiliar song patterns, memory retrieval processes must be involved. Interference with memory is 


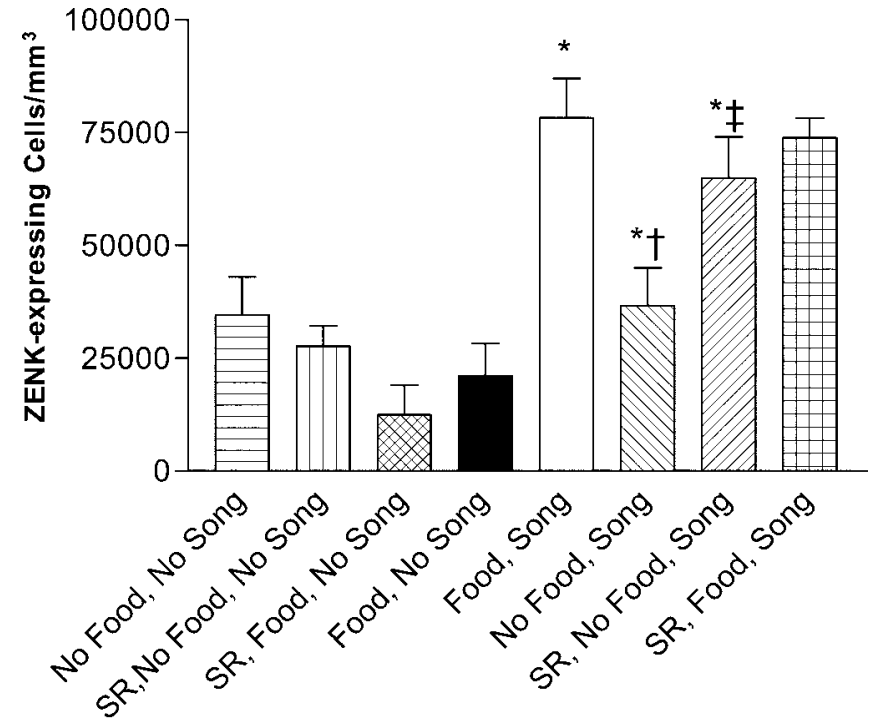

Figure 7. Quantification of ZENK-expressing cells per cubed millimeter of NCM. Groups of zebra finches were treated as indicated (see Materials and Methods), and tissue was prepared for immunocytochemical analysis of ZENK expression within the NCM. Exposure to novel song increases the number of ZENK-expressing cells (Song; indicated by *). These increases were significantly reduced by limited food access (No Food; indicated by $\dagger$ ). This limited food access effect was reversed by pretreatment with the $\mathrm{CB}_{1}$ cannabinoid receptor-selective antagonist SR141716A (SR; 3 mg/kg, i.m.; indicated by f). No Song, No Food and SR, No Song, No Food controls did not significantly differ from No Song, Food. Group SR, Food, Song did not differ from group Food, Song.

a well characterized effect of cannabinoids in mammalian species (Iversen, 2003). Together, these facts support the possibility that impaired memory retrieval plays a role in the endocannabinoidassociated decreased NCM ZENK responsiveness that we have measured. Use of a songbird model, based on an animal that produces and responds to a learned form of vocal communication, should prove uniquely useful in studying cannabinoid effects on learning and memory, especially within the context of late postnatal CNS development when song patterns are memorized and practiced (Soderstrom and Johnson, 2003).

\section{References}

Berger A, Crozier G, Bisogno T, Cavaliere P, Innis S, Di Marzo V (2001) Anandamide and diet: inclusion of dietary arachidonate and docosahexaenoate leads to increased brain levels of the corresponding $\mathrm{N}$-acylethanolamines in piglets. Proc Natl Acad Sci USA 98:6402-6406.

Berry EM, Mechoulam R (2002) Tetrahydrocannabinol and endocannabinoids in feeding and appetite. Pharmacol Ther 95:185-190.

Bonke BA, Bonke D, Scheich H (1979) Connectivity of the auditory forebrain nuclei in the guinea fowl (Numida meleagris). Cell Tissue Res 200:101-121.

Chew SJ, Vicario DS, Nottebohm F (1996) A large-capacity memory system that recognizes the calls and songs of individual birds. Proc Natl Acad Sci USA 93:1950-1955.

Clayton DF (2000) The genomic action potential. Neurobiol Learn Mem 74:185-216.

Cole AJ, Saffen DW, Baraban JM, Worley PF (1989) Rapid increase of an immediate early gene messenger RNA in hippocampal neurons by synaptic NMDA receptor activation. Nature 340:474-476.

Cota D, Marsicano G, Tschop M, Grubler Y, Flachskamm C, Schubert M, Auer D, Yassouridis A, Thone-Reineke C, Ortmann S, Tomassoni F, Cervino C, Nisoli E, Linthorst AC, Pasquali R, Lutz B, Stalla GK, Pagotto U (2003) The endogenous cannabinoid system affects energy balance via central orexigenic drive and peripheral lipogenesis. J Clin Invest 112: 423-431.

Di Marzo V, Melck D, Bisogno T, De Petrocellis L (1998) Endocannabi- noids: endogenous cannabinoid receptor ligands with neuromodulatory action. Trends Neurosci 21:521-528.

Di Marzo V, Bisogno T, De Petrocellis L, Melck D, Orlando P, Wagner JA, Kunos G (1999) Biosynthesis and inactivation of the endocannabinoid 2 -arachidonoylglycerol in circulating and tumoral macrophages. Eur J Biochem 264:258-267.

Di Marzo V, Hill MP, Bisogno T, Crossman AR, Brotchie JM (2000) Enhanced levels of endogenous cannabinoids in the globus pallidus are associated with a reduction in movement in an animal model of Parkinson's disease. FASEB J 14:1432-1438.

Di Marzo V, Goparaju SK, Wang L, Liu J, Batkai S, Jarai Z, Fezza F, Miura GI, Palmiter RD, Sugiura T, Kunos G (2001) Leptin-regulated endocannabinoids are involved in maintaining food intake. Nature 410:822-825.

Di Marzo V, Bifulco M, De Petrocellis L (2004) The endocannabinoid system and its therapeutic exploitation. Nat Rev Drug Discov 3:771-784.

Egertova M, Elphick MR (2000) Localisation of cannabinoid receptors in the rat brain using antibodies to the intracellular C-terminal tail of CB1. J Comp Neurol 422:159-171.

Gerdeman GL, Lovinger DM (2003) Emerging roles for endocannabinoids in long-term synaptic plasticity. Br J Pharmacol 140:781-789.

Giuffrida A, Parsons LH, Kerr TM, Rodriguez de Fonseca F, Navarro M, Piomelli D (1999) Dopamine activation of endogenous cannabinoid signaling in dorsal striatum. Nat Neurosci 2:358-363.

Hanus L, Avraham Y, Ben-Shushan D, Zolotarev O, Berry EM, Mechoulam R (2003) Short-term fasting and prolonged semistarvation have opposite effects on 2-AG levels in mouse brain. Brain Res 983:144-151.

Higgs S, Williams CM, Kirkham TC (2003) Cannabinoid influences on palatability: microstructural analysis of sucrose drinking after delta(9)tetrahydrocannabinol, anandamide, 2-arachidonoyl glycerol and SR141716. Psychopharmacology (Berl) 165:370-377.

Hoffman AF, Lupica CR (2000) Mechanisms of cannabinoid inhibition of $\mathrm{GABA}_{\mathrm{A}}$ synaptic transmission in the hippocampus. J Neurosci 20:2470-2479.

Hoffman AF, Lupica CR (2001) Direct actions of cannabinoids on synaptic transmission in the nucleus accumbens: a comparison with opioids. J Neurophysiol 85:72-83.

Iversen L (2003) Cannabis and the brain. Brain 126:1252-1270.

Johnson F, Rashotte M (2002) Food availability but not cold ambient temperature affects undirected singing in adult male zebra finches. Physiol Behav 76:9-20.

Kirkham TC, Williams CM, Fezza F, Di Marzo V (2002) Endocannabinoid levels in rat limbic forebrain and hypothalamus in relation to fasting, feeding and satiation: stimulation of eating by 2-arachidonoyl glycerol. Br J Pharmacol 136:550-557.

Marsicano G, Goodenough S, Monory K, Hermann H, Eder M, Cannich A, Azad SC, Cascio MG, Gutierrez SO, van der Stelt M, Lopez-Rodriguez ML, Casanova E, Schutz G, Zieglgansberger W, Di Marzo V, Behl C, Lutz B (2003) CB1 cannabinoid receptors and on-demand defense against excitotoxicity. Science 302:84-88.

Matias I, Di Marzo V (2004) Endocannabinoids, food-intake and body weight. In: Recent advances in pharmacology and physiology of cannabinoids (Wenger T, ed), pp 217-236. Kerala, India: Research Signpost.

Matias I, Leonhardt M, Lesage J, De Petrocellis L, Dupouy JP, Vieau D, Di Marzo V (2003) Effect of maternal under-nutrition on pup body weight and hypothalamic endocannabinoid levels. Cell Mol Life Sci 60:382-389.

Mello C, Nottebohm F, Clayton D (1995) Repeated exposure to one song leads to a rapid and persistent decline in an immediate early gene's response to that song in zebra finch telencephalon. J Neurosci 15:6919-6925.

Mello CV, Clayton DF (1994) Song-induced ZENK gene expression in auditory pathways of songbird brain and its relation to the song control system. J Neurosci 14:6652-6666.

Mello CV, Ribeiro S (1998) ZENK protein regulation by song in the brain of songbirds. J Comp Neurol 393:426-438.

Mooney R (1999) Sensitive periods and circuits for learned birdsong. Curr Opin Neurobiol 9:121-127.

Muller CM, Scheich H (1987) GABAergic inhibition increases the neuronal selectivity to natural sounds in the avian auditory forebrain. Brain Res 414:376-380.

Muller CM, Scheich H (1988) Contribution of GABAergic inhibition to the response characteristics of auditory units in the avian forebrain. J Neurophysiol 59:1673-1689. 
Pertwee RG (1999) Pharmacology of cannabinoid receptor ligands. Curr Med Chem 6:635-664.

Rashotte ME, Sedunova EV, Johnson F, Pastukhov IF (2001) Influence of food and water availability on undirected singing and energetic status in adult male zebra finches (Taeniopygia guttata). Physiol Behav 74:533-541.

Reiner AP, Perkel DJ, Bruce L, Butler AB, Csillag A, Kunzel W, Medina L, Paxinos G, Shimizu T, Striedter G, Wild M, Ball GF, Durand S, Güntürkün O, Lee DW, Mello CV, Powers A, White SA, Hough G, Kubikova $\mathrm{L}$, et al. (2004) Revised nomenclature for avian telencephalon and some related brainstem nuclei. J Comp Neurol 473:377-414.

Salzet M, Breton C, Bisogno T, Di Marzo V (2000) Comparative biology of the endocannabinoid system possible role in the immune response. Eur J Biochem 267:4917-4927.

Soderstrom K, Johnson F (2000) CB1 cannabinoid receptor expression in brain regions associated with zebra finch song control. Brain Res 857:151-157.

Soderstrom K, Johnson F (2001) The zebra finch CB1 cannabinoid receptor: pharmacology and in vivo and in vitro effects of activation. J Pharmacol Exp Ther 297:189-197.

Soderstrom K, Johnson F (2003) Cannabinoid exposure alters learning of zebra finch vocal patterns. Brain Res Dev Brain Res 142:215-217.

Stripling R, Volman SF, Clayton DF (1997) Response modulation in the zebra finch neostriatum: relationship to nuclear gene regulation. J Neurosci 17:3883-3893.
Suzuki T, Ito T, Wellman SE, Ho IK (1996) An autoradiographic study of $\left[{ }^{3} \mathrm{H}\right]$ flunitrazepam binding sites in the brain of rat made tolerant to and dependent on pentobarbital. Eur J Pharmacol 295:169-179.

Tsou K, Brown S, Sanudo-Pena MC, Mackie K, Walker JM (1998) Immunohistochemical distribution of cannabinoid CB1 receptors in the rat central nervous system. Neuroscience 83:393-411.

Valenti M, Vigano D, Casico MG, Rubino T, Steardo L, Parolaro D, Di Marzo V (2004) Differential diurnal variations of anandamide and 2-arachidonyl-glycerol levels in rat brain. Cell Mol Life Sci 61:945-950.

Vates GE, Broome BM, Mello CV, Nottebohm F (1996) Auditory pathways of caudal telencephalon and their relation to the song system of adult male zebra finches. J Comp Neurol 366:613-642.

Wager-Miller J, Westenbroek R, Mackie K (2002) Dimerization of G protein-coupled receptors: CB1 cannabinoid receptors as an example. Chem Phys Lipids 121:83-89.

Whitney O, Soderstrom K, Johnson F (2000) Post-transcriptional regulation of zenk expression associated with zebra finch vocal development. Brain Res Mol Brain Res 80:279-290.

Whitney O, Soderstrom K, Johnson F (2003) CB1 cannabinoid receptor activation inhibits a neural correlate of song recognition in an auditory/perceptual region of the zebra finch telencephalon. J Neurobiol 56:266-274.

Zann R (1996) The zebra finch: a synthesis of field and laboratory studies. New York: Oxford UP. 